\title{
ALTERAÇÃO DE ATRIBUTOS FÍSICOS EM LATOSSOLO COM APLICAÇÃO SUPERFICIAL DE ESCÓRIA DE ACIARIA, LAMA CAL, LODOS DE ESGOTO E CALCÁRIO(1)
}

\author{
Juliano Corulli Corrêa ${ }^{(2)}$, Leonardo Theodoro Bull ${ }^{(3)}$, Carlos \\ Alexandre Costa Crusciol ${ }^{(3)} \&$ Maria Helena Moraes $^{(3)}$.
}

\begin{abstract}
RESUMO
Os resíduos industriais e urbanos podem atuar como condicionadores do solo, pois possuem a capacidade de alterar suas propriedades físicas. Contudo, não há referência para os atributos físicos do solo quando esses resíduos são aplicados sobre a superfície do solo no sistema plantio direto. O objetivo deste trabalho foi avaliar o efeito da aplicação superficial de escória de aciaria, lama cal, lodos de esgoto e calcário nos atributos físicos de um Latossolo Vermelho distrófico sob sistema plantio direto. Os tratamentos foram constituídos por quatro resíduos: lodos de esgoto centrifugado - LC e de biodigestor - LB, escória de aciaria - E, e lama cal - Lcal, interagindo com quatro doses $\left(0,2,4 \mathrm{e} 8 \mathrm{t} \mathrm{ha}^{-1}\right.$, aplicadas na forma seca) mais uma testemunha (controle), constituída da aplicação de $2 \mathrm{t} \mathrm{ha}^{-1}$ de calcário. O delineamento experimental foi em blocos casualizados no esquema fatorial $4 \times 4+1$, com quatro repetições. A presença de Ca na composição de lama cal, lodo de esgoto centrifugado, escória de aciaria e calcário permite o aumento da agregação das partículas, diâmetro médio ponderado, índice de estabilidade de agregados, porosidade e retenção de água, sendo essas alterações distintas para cada fonte, dose e profundidade de reação no solo. A aplicação superficial da lama cal na dose de $8 \mathrm{t} \mathrm{ha}{ }^{-1}$, após 27 meses de reação, proporcionou a maior agregação das partículas no solo, desde a superfície até $40 \mathrm{~cm}$ de profundidade.
\end{abstract}

Termos de indexação: agregação, diâmetro médio ponderado, retenção de água no solo, cálcio, matéria orgânica.

\footnotetext{
(1) Parte da tese do primeiro autor. Com apoio financeiro da FAPESP. Recebido para publicação em novembo de 2007 e aprovado em janeiro de 2009

(2) Embrapa Suínos e Aves, BR 153, km 110, Caixa Postal 121, Vila Tamanduá, CEP 89700-000, Concórdia - SC. Email: juliano@cnpsa.embrapa.br

(3) Faculdade de Ciências Agronômicas, Universidade Estadual Paulista - UNESP. Fazenda Experimental Lageado, Caixa Postal 237, CEP 18603-970 Botucatu (SP). E-mails: bull@fca.unesp.br; crusciol@fca.unesp.br; moraes@fca.unesp.br
} 


\title{
SUMMARY: OXISOL PHYSICAL ATTRIBUTES AFFECTED BY SURFACE APPLICATION OF FLUE DUST, AQUEOUS LIME, SEWAGE SLUDGES AND LIMESTONE
}

\begin{abstract}
The residues flue dust, aqueous lime and sewage sludge (centrifuge and biodigestor) may affect soil physical attributes. The use of industrial and urban residues in soil, with emphasis to sewage sludge, was done in tilled soil, and there are no repports on soil physical attributes affected by these residues on soil surface in no-till system The goal of this study was to evaluate the physical attributes of a an Oxisol in no-till system by surface dispoasal of sewage sludge, flue dust, aqueous lime. The experiment was carried out under field conditions during the agricultural years of 2002 to 2005. Treatments were four residues sewage sludge centrifuged, sewage sludge biodigestor, flue dust and aqueous lime application on soil surface in four rates $\left(0,2,4\right.$ e $\left.8 t h \mathrm{~h}^{-1}\right)$ and one control treatment, with $2 t h \mathrm{a}^{-1}$ of dolomitc limestone. The experiment was set up in randomized block design, using $4 \times 4+1$ factorial design, with four replications. The Ca present in aqueous lime, sewage sludge centrifuged, flue dust and limestone increase aggregation of soil particles, DMP, IEA, total soil porosity and water retention, at this alteration

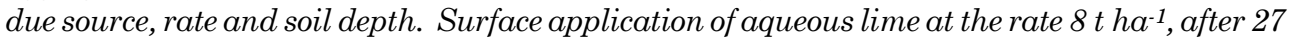
reaction month, allow the better aggregation of soil particles, since the surface into $40 \mathrm{~cm}$ depth.
\end{abstract}

Indexterms: Aggregation, mean pondered diameter, soil water retention, calcium, organic matter.

\section{INTRODUÇÃO}

A aplicação de calcário aumenta o pH do solo, conduzindo à formação de cargas negativas nos coloides, com especial ênfase nos solos onde essas cargas são dependentes de $\mathrm{pH}$, como nos Latossolos, o que pode favorecer a dispersão de argilas (Albuquerque et al., 2003). No entanto, essa mesma calagem fornece $\mathrm{Ca}^{2+}$, que funciona como ligante entre as partículas de argila (Oliveira, 2008), permitindo dessa forma maior agregação do solo (Castro Filho \& Logan, 1991). Além desse efeito direto, a calagem apresenta o efeito indireto, por aumentar a fitomassa das culturas, podendo assim aumentar o teor de matéria orgânica no solo e favorecer a atividade microbiana, o que aumentaria, também, a agregação do solo (Castro Filho et al., 1998; Santos et al., 1999).

Assim como o calcário, há outros materiais corretivos, como a escória de aciaria, lama cal e lodos de esgoto, que podem possibilitar as mesmas modificações químicas do solo, com a vantagem de serem mais reativos e apresentarem maior mobilidade no perfil quando aplicados em superfície em áreas de plantio direto (Corrêa et al., 2007, 2008 a,b). Não existem trabalhos relatando o efeito da escória de aciaria, lama cal e lodos de esgoto aplicados sobre a superfície do solo em sistema plantio direto, com especial enfoque para as propriedades físicas do solo, não sendo conhecidas, portanto, suas respostas ao longo do perfil do solo.

Os benefícios proporcionados pelo sistema plantio direto às propriedades físicas do solo advêm da deposição da cobertura vegetal em superfície, que favorece o aumento da matéria orgânica, oferecendo ambiente menos oxidativo e permitindo o menor contato dos resíduos com o solo, o que diminui a taxa de decomposição da matéria orgânica (Miyazawa et al., 2000). As consequências dessas alterações são a maior agregação das partículas, infiltração e retenção da água no solo e o menor escoamento superficial e erosão hídrica (Stone \& Silveira, 1999).

Como a utilização de escória de aciaria, lama cal e lodos de esgoto e a adoção do sistema plantio direto são práticas que elevam os teores de Ca e matéria orgânica no solo (Carvalho-Pupatto et al., 2004; Lovato et al., 2004; Souza et al., 2005), e sabendo que esses fatores são responsáveis pela maior agregação e estabilidade das partículas do solo (Corrêa, 2002), a associação dessas práticas agrícolas pode melhorar os atributos físicos do solo.

Os resultados de alterações físicas do solo, envolvendo lodo de esgoto, dizem respeito ao sistema convencional de plantio e com incorporação desses resíduos (Melo et al., 2004; Souza et al., 2005). Melo et al. (2004) demonstram que a aplicação de lodo de esgoto em solos tropicais resulta em aumento da macroporosidade. Já Camilotti et al. (2006) não verificaram efeito da aplicação de lodo de esgoto nos atributos físicos do solo, em razão da não associação desses resíduos com a matéria orgânica. Diante do exposto, este trabalho teve o objetivo de avaliar alterações de atributos físicos de um Latossolo Vermelho distrófico sob sistema plantio direto em resposta à aplicação superficial de lodos de esgoto, lama cal e escória de aciaria.

\section{MATERIAL E MÉTODOS}

O experimento foi realizado durante os anos agrícolas de 2002 a 2004, na Fazenda Experimental 
Lageado, pertencente à Faculdade de Ciências Agronômicas da UNESP, Botucatu-SP, na latitude de $22^{\circ} 51$ ' 15 " S, longitude de $48^{\circ} 26^{\prime} 30$ " W e altitude de $740 \mathrm{~m}$. O clima predominante é do tipo Cwa, caracterizado como clima temperado úmido com inverno seco e verão quente (temperatura média do ar no mês mais quente $>22^{\circ} \mathrm{C}$ e a do mês mais frio entre 3 e $18^{\circ} \mathrm{C}$ ), de acordo com a classificação climática de Köppen.

O trabalho foi implantado sob sistema plantio direto, em Latossolo Vermelho distrófico textura média fase campo subtropical relevo suave ondulado, de acordo com os critérios do Sistema Brasileiro de Classificação de Solos (Embrapa, 1999). A amostragem para caracterização química e textural do solo foi realizada em 15 pontos aleatórios da área para compor uma amostra de solo, apresentando as seguintes características: teores de MO de 16, 18, 15 e $10 \mathrm{~g} \mathrm{dm}^{-3}$, teores de $\mathrm{Ca}^{2+}$ de $12,19,13$ e $12 \mathrm{mmol}_{\mathrm{c}} \mathrm{dm}^{-3}$ e teores de argila de $325,325,347$ e $360 \mathrm{~g} \mathrm{~kg}^{-1}$ para as camadas de $0-5,5-10,10-20$ e $20-40 \mathrm{~cm}$ de profundidade, de acordo com método descrito por Raij et al. (2001) e Embrapa (1997).

Os tratamentos foram constituídos por quatro resíduos, sendo dois tipos de lodos de esgoto: centrifugado - LC, com adição de cal virgem $(\mathrm{CaO})$ da ETE de São José dos Campos e de biodigestor LB, com adição de polieletrólitos da ETE de Barueri; e dois tipos de resíduos industriais: escória de aciaria - E, da Empresa Mannesmann de fabricação de tubos de aço em Belo Horizonte, e lama cal - Lcal, da Empresa de celulose Luwarcel - Lcal, da cidade de Lençóis Paulistas. A análise química dos resíduos

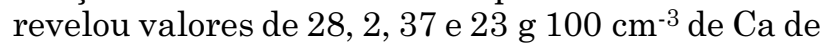
matéria seca e $26,50,3$ e $1 \mathrm{~g} 100 \mathrm{~cm}^{-3}$ de matéria orgânica de material seco para os resíduos LC, LB, Lcal e E, respectivamente. Para esses resíduos foram empregadas as doses de $0,2,4$ e $8 \mathrm{t} \mathrm{ha}^{-1}$, calculados em material seco. Como tratamento controle aplicouse calcário dolomítico (280 g kg-1 de CaO, 230 g kg-1 de $\mathrm{Mg} \mathrm{O}$ e PRNT de 70 \%) na dose recomendada para elevar a saturação por bases a $70 \%\left(2 \mathrm{t} \mathrm{ha}^{-1}\right)$, até a profundidade de $0-20 \mathrm{~cm}$.

Os tratamentos foram distribuídos no campo em delineamento em blocos ao acaso com esquema fatorial $4 \times 4+1$, com quatro repetições. Em cada bloco, as parcelas foram dimensionadas com $6 \mathrm{~m}$ de largura por $7 \mathrm{~m}$ de comprimento, deixando-se $1 \mathrm{~m}$ entre as parcelas do mesmo bloco e $3 \mathrm{~m}$ entre blocos.

O experimento iniciou-se com a dessecação do feijãoguandu, semeado com a finalidade de produzir matéria seca para o sistema plantio direto. Em seguida, os resíduos foram aplicados a lanço, em agosto de 2002, sobre a palhada do guandu. A aplicação antecedeu três meses a semeadura da soja na safra 2002/2003. A precipitação pluvial nesse período correspondeu a $270 \mathrm{~mm}$. De 2003 até a amostragem, em novembro de 2004, o volume de precipitação pluvial atingiu $2.850 \mathrm{~mm}$.
Durante o período do experimento, foram realizadas duas semeaduras de soja (safras 2002/2003 e 2003/ 2004) aplicando-se adubação de $300 \mathrm{~kg} \mathrm{ha}^{-1}$ do fertilizante formulado 00-20-10, com sementes inoculadas com Bradyrhizobium japonicum. Durante o inverno, foi cultivada, por dois anos, aveia-preta (2003 e 2004), aplicando-se adubação nitrogenada no sulco de semeadura (100 kg ha-1 de ureia), com a finalidade de formação de palhada. Depois do segundo cultivo da cultura de aveia, em novembro de 2004, após dois anos da aplicação dos tratamentos (27 meses de reação), realizou-se a amostragem de solo para a caracterização química e física nas profundidades de 0-5, 5-10, 1020 e 20-40 cm. Para a amostragem química, utilizouse um trado do tipo sonda, coletando-se quatro amostras por parcela, para constituir as amostras compostas, para determinação dos teores de Ca e MO, conforme descrito por Raij et al. (2001). Para caracterização das propriedades físicas com estrutura de solo indeformada, foram utilizados anéis volumétricos de $2,5 \mathrm{~cm}$ de altura, nas profundidades de $0-5$ e $5-10 \mathrm{~cm}$, e de $5 \mathrm{~cm}$ para as profundidades de 10-20 e 20-40 cm, ambos de 4,8 cm de diâmetro interno. Para obtenção das amostras com estrutura de solo deformada, foram retiradas quatro amostras por parcela, de $125 \mathrm{~g}$, para formar uma amostra composta de $500 \mathrm{~g}$.

Nas amostras com estrutura indeformada de solo, obtidas com anéis volumétricos, foram determinados o Diâmetro Médio Ponderado (DMP), Índice de Estabilidade de Agregados (IEA), de acordo com método proposto por Castro Filho (2002), a porosidade total e retenção de água a 0,006 $\mathrm{MPa}$, conforme método da Embrapa (1997). Nas amostras com estrutura de solo deformada, foi determinada a agregação por peneiramento de solo seco, em jogo de peneiras com diferentes malhas, de acordo com método da Embrapa (1997).

Os resultados foram submetidos à análise de variância e posterior regressão, ajustando-se as equações aos dados obtidos, adotando-se como critério para escolha do modelo a interação por meio do teste $\mathrm{F}$ a 1 e $5 \%$, e a magnitude dos coeficientes de determinação (Banzato \& Kronka, 1989), sendo os resultados analisados pelo programa Sigmaplot 8.0. Todos os tratamentos foram comparados com o controle-C calcário pelo Teste de Média DMS. a 1 e 5 \% (Banzato \& Kronka, 1989), utilizando o programa Sisvar 4,2. Para a análise de correlação, adotaram-se o método de Pearson, utilizando 68 amostras, e o programa Sigmastat 3.11. Entre as camadas do solo não foram realizadas análises estatísticas.

\section{RESULTADOS E DISCUSSÃO}

A aplicação superficial de escória de aciaria (E), lama cal (Lcal), lodos de esgoto (LB e LC) e do calcário, principalmente na dose de $8 \mathrm{t} \mathrm{ha}^{-1}$, constatou aumento 
na agregação das partículas do solo, resultando em maior quantidade de agregados retidos na peneira de 4,0-2,0 mm e, consequentemente, menor quantidade na classe de 0,05-0,025 mm (Figura 1).
O efeito do calcário foi maior na profundidade 5$10 \mathrm{~cm}$. O tratamento calcário conferiu maior percentagem de agregados em relação à dose zero dos resíduos, nas profundidades de $0-5$ e $5-10 \mathrm{~cm}$, na

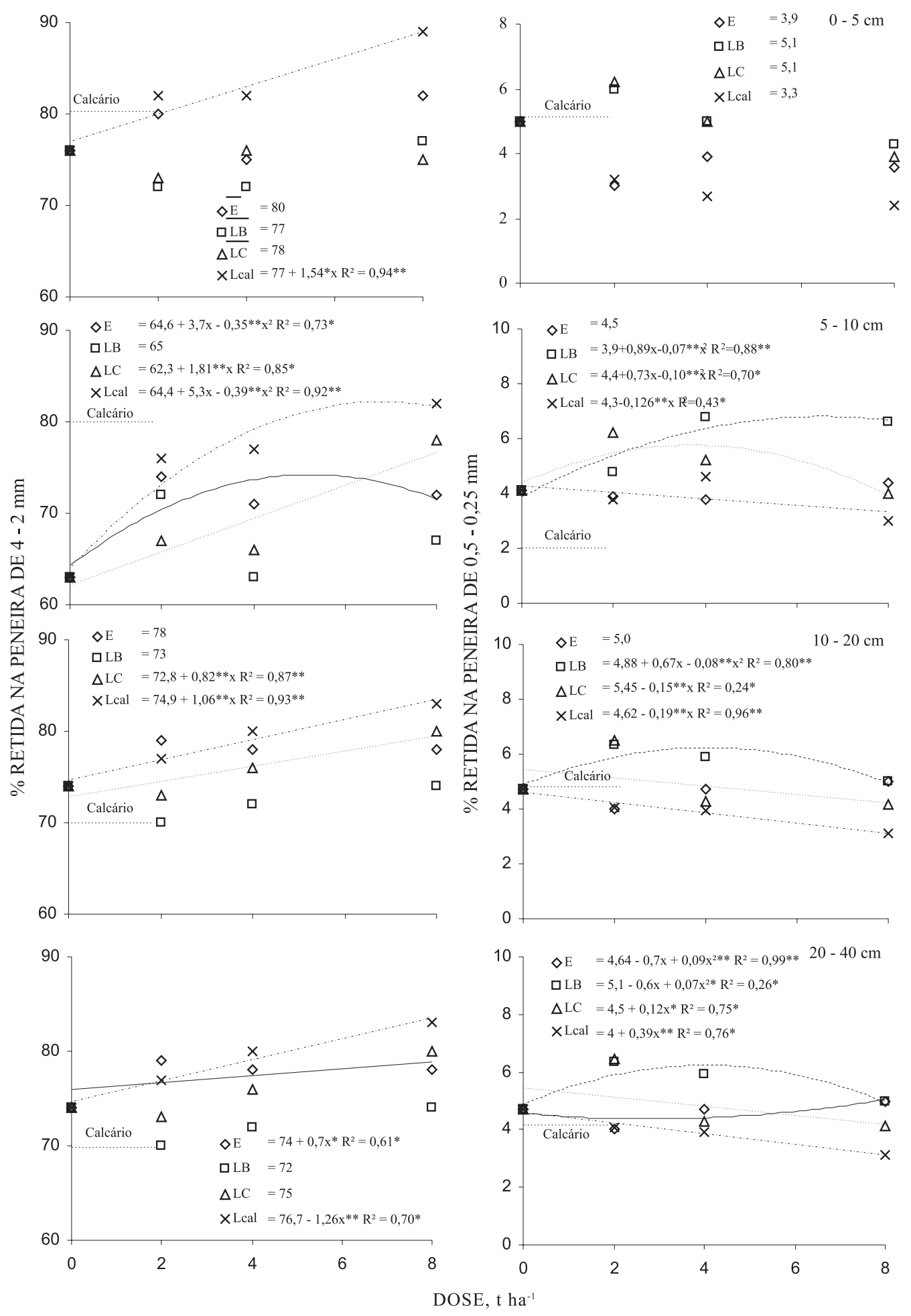

Figura 1. Percentagem de agregados retidos nas peneiras de 4-2 e 0,5-0,20 mm em função da aplicação dos resíduos e calcário aos 27 meses após a aplicação. As siglas E, LB, LC e Lcal são escória de aciaria, lodo de esgoto de biodigestor, lodo de esgoto centrifugado e lama cal, respectivamente. 
peneira de 4,0-2,0 $\mathrm{mm}$, o que permite inferir que esse tratamento, como esperado, também promove agregação das partículas do solo em profundidade quando aplicado sobre a superfície do solo em plantio direto.

$\mathrm{O}$ tratamento Lcal foi o que apresentou a maior percentagem de agregação do solo, na peneira de 4,0$2,0 \mathrm{~mm}$, entre os resíduos e o calcário, em todas as profundidades (Figura 1), sugerindo ser um condicionador de solo para melhoria da agregação. Os outros resíduos que apresentaram comportamento crescente, na peneira de 4,0-2,0 $\mathrm{mm}$, foram a escória de aciaria (E) nas camadas de 5-10 e 20-40 cm e o lodo de esgoto (LC) nas camadas de 10-20 e 20-40 cm. Portanto, os resíduos Lcal, LC e E, todos contendo Ca em quantidades similares ou maiores que a do calcário para a mesma quantidade de produto, além de um $\mathrm{pH}$ alcalino, podem ser considerados condicionadores do solo, corroborando os resultados encontrados por Melo et al. (2004) e Souza et al. (2005) para lodo de esgoto incorporado.

Verificou-se correlação entre os teores de Ca no solo e agregação, sendo positiva para as partículas de 4-2 $\mathrm{mm}$ e negativa para as de $0,5-0,25 \mathrm{~mm}$, com exceção para camada de $20-40 \mathrm{~cm}$. Os valores de correlação foram de: $\mathrm{r}=0,33^{* *} \mathrm{e} \mathrm{r}=-0,35^{* *}$ para camada de $0-5 \mathrm{~cm}$, de $\mathrm{r}=0,63^{* *}$ e $\mathrm{r}=-0,30^{*}$ para 5 $10 \mathrm{~cm}$, de $\mathrm{r}=0,45^{* *}$ e $\mathrm{r}=-0,28^{*}$ para $10-20 \mathrm{~cm} \mathrm{e}$ efeito não-significativo e de $\mathrm{r}=0,31^{* *}$ para $20-40 \mathrm{~cm}$ de profundidade, utilizando-se 68 amostras. Não houve efeito de correlação significativo entre o teor de matéria orgânica no solo e agregação de partículas de tamanho de $4-2$ e de $0,5-0,25 \mathrm{~mm}$ nas quatro camadas amostradas no perfil do solo.

Houve aumento do teor de Ca no solo com a aplicação superficial de doses crescentes dos resíduos e do calcário na dose de $2 \mathrm{t} \mathrm{ha}^{-1}$ (Figura 2), fator que ajuda a agregação das partículas (Figura 1). Esse aumento no teor de Ca no solo pela aplicação superficial de doses dos resíduos é justificado pela presença no Lcal, na ordem de $37 \%$ de Ca, no LC em $28 \%$ e na E em $23 \%$. Cátions como Ca e Mg formam pontes que ligam os polímeros da matéria orgânica com a superfície dos coloides do solo, com pH acima de 5,4, quando $\mathrm{Ca}$ e o $\mathrm{Mg}$ podem dominar o complexo de troca, aumentando novamente a agregação (Castro Filho, 2002; Oliveira, 2008). Vale destacar ainda que o $\mathrm{Ca}$ também pode fazer ligações entre os grupos fenólicos e carboxílicos da matéria orgânica com os coloides do solo, em razão do aumento de pH (Castro Filho \& Logan, 1998).

A aplicação superficial do resíduo Lcal na dose de $8 \mathrm{t} \mathrm{ha}^{-1}$ proporcionou a maior formação de agregados de tamanho entre 4-2 $\mathrm{mm}$ nas quatro camadas amostradas (Figura 1). Vale lembrar que esse resíduo apresentou o maior teor de $\mathrm{Ca}(37 \%)$. O tratamento com calcário na dose de $2 \mathrm{t} \mathrm{ha}^{-1}$ foi semelhante aos tratamentos com Lcal nas doses de 2 e $4 \mathrm{t} \mathrm{ha}^{-1} \mathrm{e}$ inferior ao de dose de $8 \mathrm{t} \mathrm{ha}^{-1}$ na camada de $0-5 \mathrm{~cm}$ e semelhante ao Lcal na dose de $8 \mathrm{t} \mathrm{ha}^{-1}$ para camada de $5-10 \mathrm{~cm}$ de profundidade, sendo superior aos demais tratamentos com os resíduos LC, E e LB nessas duas camadas superficiais; no entanto, a calagem superficial mantém essa eficiência até a profundidade de $10 \mathrm{~cm}$, quando aplicado sobre a superfície do solo no sistema plantio direto, resultado que pode ser justificado em razão de o tratamento calcário mostrar-se inferior a todos os tratamentos, com exceção do tratamento LB nas doses de 2 e $4 \mathrm{t} \mathrm{ha}^{-1}$, nas camadas de $10-20$ e 20 $40 \mathrm{~cm}$ de profundidade.

Mesmo sem haver correlação entre a MO e a agregação no solo, é importante ressaltar que a aplicação superficial de doses crescentes dos resíduos LC, LB, E, Lcal e do calcário na dose de $2 \mathrm{t} \mathrm{ha}^{-1}$ proporcionou aumento no teor dessa variável no solo, principalmente na superfície, nas camadas de $0-5$ e 5-10 cm de profundidade (Figura 2). Assim, a presença de MO ajudaria a formação de macroagregados jovens, pela ação dos microrganismos na decomposição dos polissacarídeos, dos quais origina o mucigel, proporcionando a ação cimentante entre a matéria orgânica e o solo (Mielniczuk, 1999), além de ela possuir maior superfície específica e capacidade de troca de cátions, possibilitando maior número de ligações entre as partículas de solo (Souza et al., 2005). Portanto, os fatores que podem ter aumentado a agregação são o teor de $\mathrm{Ca}$, o aumento do $\mathrm{pH}$ do solo possibilitando a hidrólise alcalina da MO e um possível estímulo da atividade biológica do solo devido a ambos os fatores.

O resíduo Lcal promoveu o aumento do diâmetro médio ponderado (DMP) nas camadas de $0-5,5-10$ e $10-20 \mathrm{~cm}$ e redução na camada $20-40 \mathrm{~cm}$ (Figura 3), lembrando que essa variável é um indicativo da estabilidade da estrutura do solo (Albuquerque et al., 2003). Essa contradição dentro do mesmo tratamento pode ser atribuída à presença dos elementos que causam a agregação e a desagregação do solo, que são o $\mathrm{Ca}^{2+} \mathrm{e}$ o $\mathrm{Na}^{+}$, na composição desse resíduo (37 e $20 \%$ ). O efeito favorável à agregação do solo até a profundidade de $20 \mathrm{~cm}$ pode ser atribuído ao $\mathrm{Ca}^{2+}$ (Figura 2), e a desagregação na última camada do solo pode ser atribuída ao $\mathrm{Na}^{+}$, uma vez que esse elemento possui alta movimentação no solo, principalmente por lixiviação, permitindo maior desagregação do solo nos locais onde se encontram os maiores teores, fato que, provavelmente, permitiu a redução no DMP na camada de 20-40 cm. Já o lodo de esgoto LB não alterou o DMP (Figura 3), diferentemente do lodo de esgoto LC, que apresentou comportamento linear crescente nas camadas de $5-10$ e $10-20 \mathrm{~cm}$, corroborando os resultados de Souza et al. (2005). Verifica-se que LB, apesar de apresentar o maior teor de MO, tem o menor teor de Ca. A escória de aciaria (E) elevou o DMP na camada de $5-10 \mathrm{~cm}$, e a dose de $5 \mathrm{t} \mathrm{ha}^{-1}$ proporcionou o maior valor para essa variável.

Verificou-se correlação entre os teores de Ca no solo e o DMP para as camada de 5-10 e de 10-20 cm de 

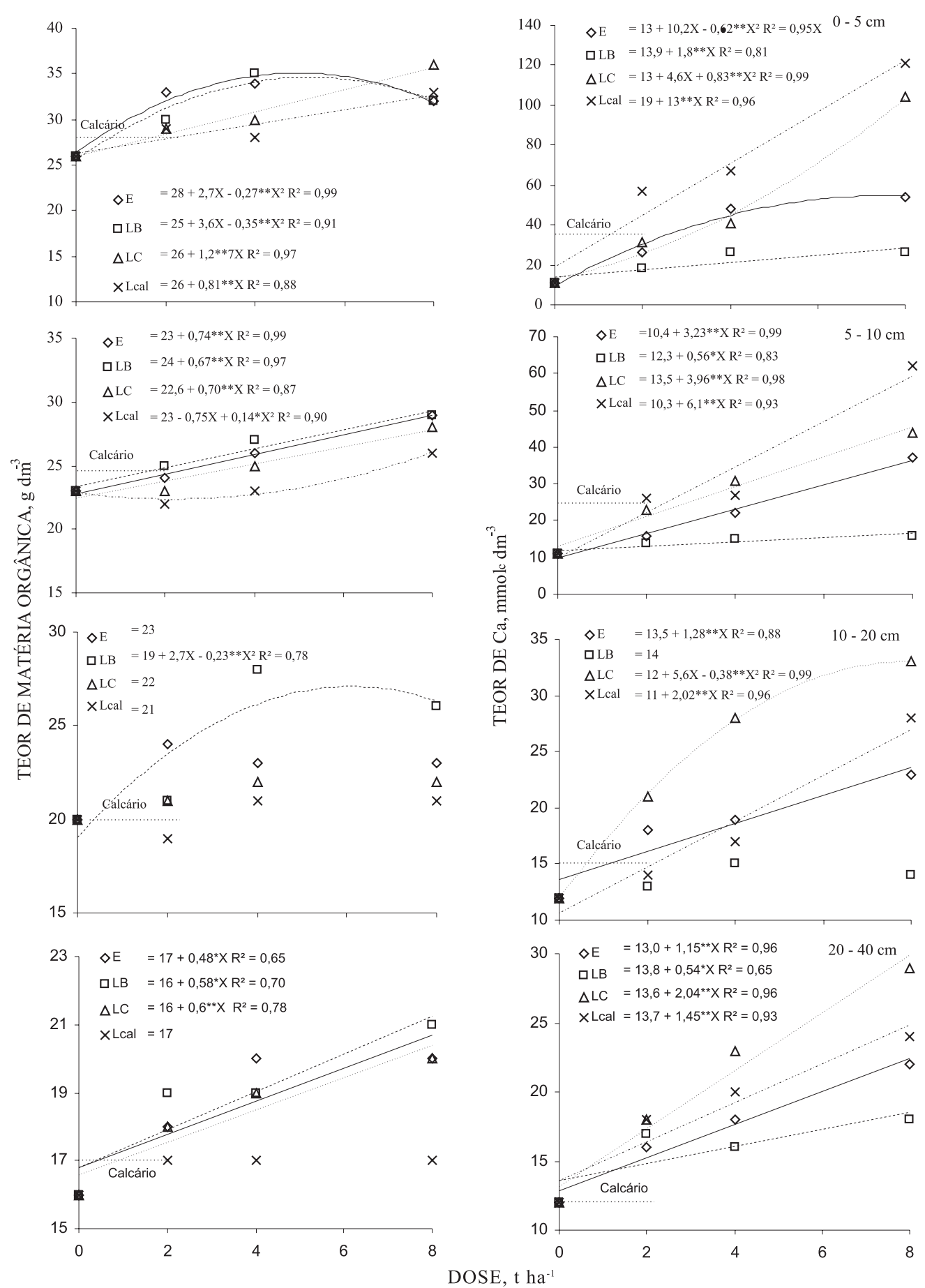

Figura 2. Teor de matéria orgânica e de cálcio no solo em função da aplicação dos resíduos e calcário aos 27 meses após a aplicação. As siglas E, LB, LC e Lcal são escória de aciaria, lodo de esgoto de biodigestor, lodo de esgoto centrifugado e lama cal, respectivamente.

profundidade, com valores de $\mathrm{r}=0,63^{* *}$ e $\mathrm{r}=-0,32^{* *}$. Para às demais não houve efeito significativo, utilizando-se 68 amostras. Não houve correlação significativa entre o teor de MO no solo e o DMP nas camadas de 0-5, 10-20 e 20-40 cm; contudo, na camada de $5-10 \mathrm{~cm}$ de profundidade, verificou-se um valor de $\mathrm{r}=0,25^{*}$ entre essas variáveis.
A aplicação superficial do calcário, no sistema plantio direto, difere da dose zero para o DMP, na profundidade de 5-10 cm, e nesta camada apresenta efeito semelhante ao dos tratamentos com Lcal nas doses de 2 e 4 t ha $^{-1}$ (Figura 3). Estes resultados da calagem nesta camada pode ser justificado pela maior agregação das partículas do solo (Figura 1). 
A aplicação superficial do lodo de esgoto LB apresentou comportamento quadrático decrescente para o índice de estabilidade de agregados (IEA) na camada superficial de $0-5 \mathrm{~cm}$, sendo a dose de $4,4 \mathrm{t} \mathrm{ha}^{-1}$ a de menor eficiência (Figura 3). Esse resultado pode ser justificado por esse resíduo (LB) apresentar $50 \%$
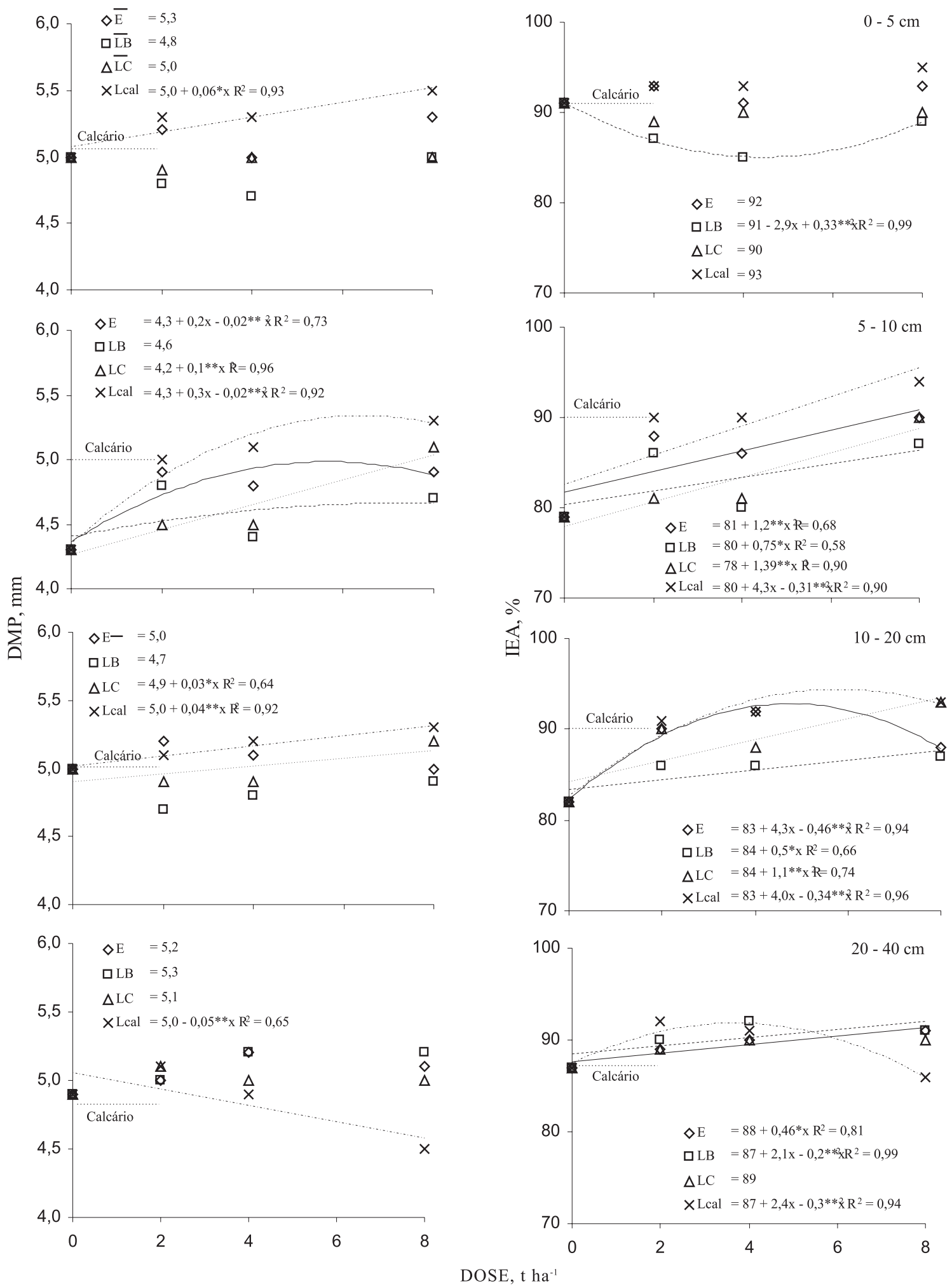

Figura 3. Diâmetro médio ponderado (DMP) e índice de estabilidade de agregados (IEA) em função da aplicação dos resíduos e calcário aos 27 meses após a aplicação. As siglas E, LB, LC e Lcal são escória de aciaria, lodo de esgoto de biodigestor, lodo de esgoto centrifugado e lama cal, respectivamente. 
de matéria orgânica em sua composição, fator que confere menor IEA a esse resíduo, devido a MO apresentar menor estabilidade em relação aos coloides do solo. Além disso, possui valor mínimo de $\mathrm{Ca}(2 \%)$. Entretanto, os efeitos de LB para IEA, a partir da próxima camada $(5-10 \mathrm{~cm})$, tornaram-se crescentes até a profundidade de $40 \mathrm{~cm}$.

O IEA aumentou com a aplicação do lodo de esgoto LC nas camadas de 5-10 e 10-20 cm e com a escória de aciaria e lama cal nessas mesmas camadas e na de $20-40 \mathrm{~cm}$ (Figura 3). Destaca-se que o tratamento Lcal foi o resíduo mais eficiente para IEA na dose de 8 t ha $^{-1}$ nas camadas de $5-10$ e $10-20$, confirmando os resultados de agregação (Figura 2) e DMP (Figura 3). Contudo, na última camada, doses acima de $4 \mathrm{t} \mathrm{ha}^{-1}$ de Lcal reduzem o IEA, em razão da presença de $\mathrm{Na}^{+}$, como já discutido para DMP. O calcário aumentou o IEA nas camadas de 5-10 e 10$20 \mathrm{~cm}$ de profundidade, sendo superior à dose zero $\mathrm{e}$ semelhante aos melhores tratamentos Lcal na dose de $8 \mathrm{t} \mathrm{ha}^{-1}$ nessas duas camadas intermediárias e ao tratamento LC na dose de $8 \mathrm{t} \mathrm{ha}^{-1}$ na camada de 10 $20 \mathrm{~cm}$ de profundidade. Estes resultados podem ser atribuídos às modificações químicas que a calagem superficial de $2 \mathrm{t} \mathrm{ha}^{-1}$ confere às camadas até $20 \mathrm{~cm}$ de profundidade, como aumento de $\mathrm{pH}$ e o fornecimento de $\mathrm{Ca}^{2+}$ sob sistema plantio direto (Corrêa et al., 2007, 2008a,b), fatores que contribuem na estabilidade de agregados (Castro Filho \& Logan, 1991; Albuquerque et al., 2003).

Para a porosidade total do solo, verificou-se aumento nos valores para os resíduos LC e Lcal até a profundidade de $40 \mathrm{~cm}$ (Figura 4), ambos com os maiores teores de Ca. Já o resíduo E, embora com teor de Ca maior que o calcário, mas mínimo de MO, não apresentou efeito significativo nas camadas de 510 e $10-20 \mathrm{~cm}$; no entanto, na camada de $0-5 \mathrm{~cm}$, foi o tratamento que causou a maior porosidade, com valor de $43,3 \%$ com a dose de $4,7 \mathrm{t} \mathrm{ha}^{-1}$ de $\mathrm{E}$.

Os efeitos positivos na porosidade total do solo, pelos resíduos LC, Lcal e E, são reflexo da agregação, do DMP e do IEA (Figuras 1 e 3).

O lodo de esgoto LB, com o maior teor de MO, mas mínimo de $\mathrm{Ca}$, apresentou efeito significativo na porosidade total apenas na camada superficial do solo, resultando no valor de $38,6 \%$ com a dose de $3,36 \mathrm{t} \mathrm{ha}^{-1}$ (Figura 4), reduzindo seu efeito a partir doses maiores. Vale ressaltar que esse resíduo apresenta de polieletrólitos em sua composição, os quais são providos, em sua maior parte, de cargas negativas e doses como a de $8 \mathrm{t} \mathrm{ha}^{-1}$ podem ter favorecido a dispersão dos coloides, fato que ocasionou a redução da porosidade total do solo nessa primeira camada. Esses resultados corroboram os de Navas et al. (1998) e são diferentes dos obtidos por Melo et al. (2004), que não encontraram resultados positivos para porosidade total com lodo de esgoto após cinco anos da aplicação. A calagem não diferiu significativamente da dose zero quanto à porosidade total do solo e, consequentemente, foi inferior aos tratamentos que apresentaram maiores valores para essa variável.

Verificou-se correlação entre os teores de Ca no solo e a porosidade total do solo, denotando valores de $\mathrm{r}=$ $0,25^{*}, 0,54^{* *}$ e $0,39^{* *}$ nas camadas de $0-5,5-10$ e $10-20 \mathrm{~cm}$ de profundidade, respectivamente, não ocorrendo efeito significativo na camada de $20-40 \mathrm{~cm}$. Não houve efeito de correlação entre a $\mathrm{MO}$ e a porosidade total no solo em nenhuma das camadas amostradas. Esse resultado permite inferir que a correlação entre o nutriente $\mathrm{Ca}$ e a porosidade total do solo confere maior aeração no solo e, provavelmente, maior infiltração de água até a profundidade de $20 \mathrm{~cm}$.

A aplicação dos resíduos e a calagem aumentaram a retenção de água no solo até a profundidade de $40 \mathrm{~cm}$, para uma tensão de 0,006 MPa (Figura 4). Segundo Logan et al. (1996) e Beutler et al. (2002), a retenção de água no solo é influenciada pela matéria orgânica decorrente de elevadas doses de lodo esgoto em solo de textura média. Na camada superficial de $0-5 \mathrm{~cm}$ os resíduos $\mathrm{LC}, \mathrm{LB}$ e $\mathrm{E}$ proporcionaram aumento de retenção de água e, a partir da dose de $2 \mathrm{t} \mathrm{ha}^{-1}$, já se inicia a estabilização para os valores dessa variável nesses três resíduos, permitindo o ajuste matemático com comportamento hiperbólico. A possível explicação para maior retenção de água no solo é consequência da melhor estruturação do solo proporcionada por esses resíduos (agregação e porosidade total), bem como da elevação dos teores de matéria orgânica no solo. Outro fator importante é que no sistema plantio direto, o não-revolvimento do solo possibilita o aparecimento de bioporos com a decomposição do sistema radicular, elevando com isso a proporção de macroporos, principalmente nas camadas mais superficiais $(0-5 \mathrm{~cm})$, fator que confere menor retenção de água, uma vez que a água é retida nos microporos do solo (essas modificações na propriedade física do solo condicionada pelo sistema plantio direto ajudaria a explicar os mesmos valores de retenção para as doses mais elevadas de cada resíduo).

Houve correlação entre os teores de Ca no solo e a retenção de água no solo, denotando valores de $\mathrm{r}=$ $0,41^{* *}, 0,46^{* *}, 0,37^{* *}$ e $0,48^{* *}$ nas camadas de $0-5$, $5-10$ e $10-20$ e $20-40 \mathrm{~cm}$ de profundidade, respectivamente. Para a correlação entre a $\mathrm{MO}$ e a retenção de água no solo, houve efeito significativo nas camadas de $0-5$ e $5-10 \mathrm{~cm}$ de profundidade, ambas com $\mathrm{r}=0,31^{* *}$; a partir da profundidade de $10 \mathrm{~cm}$ não existiu mais a correlação entre essas duas variáveis. Esse resultado permite inferir que o aumento do teor de Ca até a profundidade de $40 \mathrm{~cm}$ permitirá maior disponibilidade de água às plantas, enquanto o aumento da $\mathrm{MO}$ na maior retenção de água fica restrita, apenas, à profundidade de $10 \mathrm{~cm}$. 

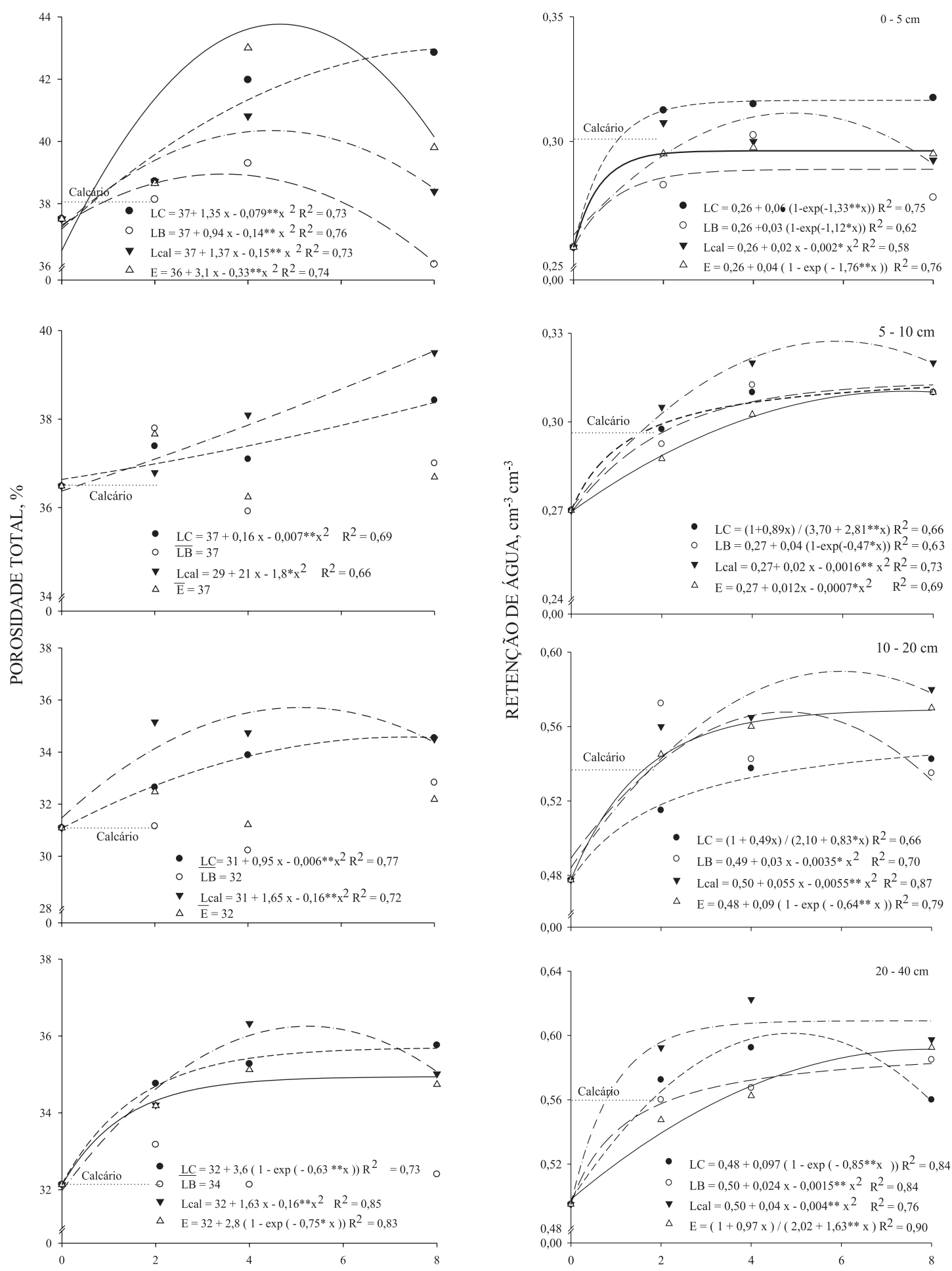

DOSE, $\mathrm{t} \mathrm{ha}^{-1}$

Figura 4. Porosidade total e retenção de água em função da aplicação dos resíduos e calcário aos 27 meses após a aplicação. As siglas E, LB, LC e Lcal são escória de aciaria, lodo de esgoto de biodigestor, lodo de esgoto centrifugado e lama cal, respectivamente.

\section{CONCLUSÃO}

1. A presença de Ca na composição da lama cal, lodo de esgoto centrifugado, escória de aciaria e calcário permite o aumento da agregação das partículas, DMP, IEA, porosidade total e retenção de água, sendo essas alterações distintas para cada fonte, dose e profundidade de reação no solo. 
2. A aplicação superficial da lama cal na dose de $8 \mathrm{t} \mathrm{ha}^{-1}$, após 27 meses de aplicação, proporcionou a maior agregação das partículas desde a superfície até $40 \mathrm{~cm}$ de profundidade no solo sob sistema plantio direto.

\section{LITERATURA CITADA}

ALBUQUERQUE, J.A.; BAYER, C.; ERNANI, P.R.; MAFRA, A.L. \& FONTANA, E.C. Aplicação de calcário e fósforo e estabilidade da estrutura de um solo ácido. R. Bras. Ci. Solo, 27:799-806, 2003.

BEUTLER, A.N.; CENTURION, J.F.; SOUZA, Z.M.; ANDRIOLI, I. \& ROQUE, C.G. Retenção de água em dois tipos de Latossolos sob diferentes usos. R. Bras. Ci. Solo, 26:829-834, 2002.

BANZATTO, D.A. \& KRONKA, S.N. Experimentação agrícola. Jaboticabal: Funep, 1989. 247p.

CAMILOTTI, F.; ANDRIOLI, I.; MARQUES, M.O.; SILVA, A.R.; TASSO JUNIOR, L.C. \& NOBILE, F.O. Atributos físicos de um Latossolo cultivado com cana-de-açúcar após aplicação de lodo de esgoto e vinhaça. Eng. Agric., 26:738747, 2006.

CARVALHO-PUPATTO, J.G.; BÜLL, L.T. \& CRUSCIOL, C.A.C. Atributos químicos do solo, crescimento radicular e produtividade do arroz de acordo com a aplicação de escórias. Pesq. Agropec. Bras., 39:1213-1218, 2004.

CASTRO FILHO, C. Atributos do solo avaliados pelos seus agregados. In: MORAES, M.E.; MÜLLER, M.M.L. \& FOLONI, J.S.S. Qualidade física do solo: Métodos de estudo - sistema de preparo e manejo do solo. Jaboticabal, Funep, 2002. 225p.

CASTRO FILHO, C. \& LOGAN, T.J. Soil aggregation mechanisms affected by liming. In: WORLD CONGRESS OF SOIL SCIENCE, 16., Montpellier, 1998. Proceedings. Montpellier, ISSS, 1998. CD-ROM.

CASTRO FILHO, C. \& LOGAN, T.J. Liming effects on the stability and erodibility of some Brazilian Oxisols. Soil Sci. Soc. Am. J., 55:1407-1413, 1991.

CASTRO FILHO, C.; MUZILli, O. \& PODANOSCHI, A.L. Estabilidade dos agregados do solo em função de sistema de plantio, rotações de culturas, preparo da amostra e teor de matéria orgânica. R. Bras. Ci. Solo, 22:527-538, 1998.

CORRÊA, J.C. Efeito de sistemas de cultivo na estabilidade de agregados de um Latossolo Vermelho-Amarelo em Querência, MT. Pesq. Agropec. Bras., 37:203-209, 2002.

CORRÊA, J.C.; BÜLL, L.T.; CRUSCIOL, C.A.C.; MAUAD, M. \& MARCELINO, M. Correção da acidez e mobilidade de íons pela aplicação superficial de escória de aciaria, lama cal, lodos de esgoto e calcário. Pesq. Agropec. Bras., 42:1307-1317, 2007.

CORRÊA, J.C.; BÜLL, L.T.; CRUSCIOL, C.A.C.; FERNANDES, D.M. \& PERES, M.G.M. Aplicação superficial de diferentes fontes de corretivos no crescimento radicular e produtividade da aveia preta. R. Bras. Ci. Solo, 32:15831590, 2008a.
CORRÊA, J.C.; BÜLL, L.T.; CRUSCIOL, C.A.C. \& TECCHIO, M.A. Aplicação superficial de escória, lama cal, lodos de esgoto e calcário na cultura da soja. Pesq. Agropec. Bras., 43:1209-1219, 2008b.

EMPRESA BRASILEIRA DE PESQUISA AGROPECUÁRIA EMBRAPA. Sistema brasileiro de classificação de solos. Brasília, Embrapa Produção de Informação; Rio de Janeiro: Embrapa Solos, 1999. 412p.

EMPRESA BRASILEIRA DE PESQUISA AGROPECUÁRIA EMBRAPA. Serviço Nacional de Pesquisa do Solo. Manual de métodos de análises de solo. Rio de Janeiro, 1997. $212 \mathrm{p}$.

LOVATO, T.; MIELNICZUK, J.; BAYER, C. \& VEZZANI, F. Adição de carbono e nitrogênio e sua relação com os estoques no solo e com o rendimento do milho em sistemas de manejo. R. Bras. Ci. Solo, 28:175-187, 2004

MELO, V.P.; BEUTLER, A.N.; SOUZA, Z.M.; CENTURION, J.F. \& MELO, W.J. Atributos físicos de Latossolos adubados durante cinco anos com biossólido. Pesq. Agropec. Bras., 39:67-72, 2004.

MIELNICZUK, J. Matéria orgânica e a sustentabilidade de sistemas agrícolas. In: SANTOS, G.A. \& CAMARGO, F.A.O. Fundamentos da matéria orgânica no solo. "Ecossistemas tropicais e subtropicais". Porto Alegre, Gênesis, 1999. 518p.

MIYAZAWA, M.; PAVAN, M.A. \& FRACHINI, J.C. Neutralização da acidez do perfil do solo por resíduos vegetais. Inf. Agron., 92: 1-8, 2000.

MORELLI, M. \& FERREIRA, E.B. Efeito do carbonato de cálcio e do fosfato diamônico em propriedades eletroquímicas e físicas de um Latossolo. R. Bras. Ci. Solo, 11:1-6, 1987.

NAVAS, A.; BERMÚDEZ, F. \& MACHÍN, J. Influence of sewage sludge application on physical and chemical properties of Gypsisols. Geoderma, 87:123-135, 1998.

OLIVEIRA, J.B. Pedologia Aplicada. 3 ed. Piracicaba: FEALQ, 2008. 592p.

RAIJ, B.van; ANDRADE, J.C.; CANTARELLA, H. \& QUAGGIO, J.A. Análise química para avaliação da fertilidade de solos tropicais. Campinas, Instituto Agronômico de Campinas, 2001. 285p.

SANTOS, G.A. \& CAMARGO, F.A.O. Fundamentos da matéria orgânica no solo. "Ecossistemas tropicais e subtropicais". Porto Alegre, Gênesis, 1999. 518p.

SOUZA, Z.M.; BEUTLER, A.N.; MELO, V.P. \& MELO, W.J. Estabilidade de agregados e resistência à penetração em Latossolos adubados por cinco anos com biossólido. R. Bras. Ci. Solo, 29:117-123, 2005.

STONE, L.F. \& SILVEIRA, P.M. Efeitos de sistema de preparo na compactação do solo, disponibilidade hídrica e comportamento do feijoeiro. Pesq. Agropec. Bras., 34:8391, 1999. 